\title{
LAYANAN KONSELING ISLAM DALAM PEMBINAAN MENTAL ORANG SAKIT DI RUMAH SAKIT UMUM AISYIYAH PADANG
}

\author{
Jasman' 1 \\ Universitas Muhammadiyah Sumatera Barat \\ Email: jasmanlimpur1987@,gmail.com \\ Syamsurizal ${ }^{2}$ \\ Universitas Muhammadiyah Sumatera Barat \\ Email: syaasy1284@yahoo.com \\ Erna Dewita ${ }^{3}$ \\ Universitas Muhammadiyah Sumatera Barat \\ Email: ernadewit4@gmail.com
}

\begin{abstract}
Abstrak
The hospital is a place that is the hope of healing people who are sick, everyone who comes to the hospital always hopes that their illness will be cured thanks to medical assistance provided by doctors. Islamic hospitals in addition to providing medical treatment also provide services in the form of religious guidance provided by experts, namely concertists, the goal is that patients who come for treatment get medical and mental services. For this reason, a concertist's role in the General Hospital is needed to continue to improve religious guidance services in accordance with the development of the existing case so as to provide inner peace for the sick. The purpose of this study was to determine the religious guidance services provided at Aisyiyah General Hospital, Padang City in terms of services and guidance provided for mental development of the sick. The target and output that will be produced are scientific articles about the role of concertists in mentally building the sick through Islamic religious guidance.
\end{abstract}

Keywords: Islamic Counselor, Mental Development, Islamic Spirituality, Soul Purification

\begin{abstract}
Abstrak
Rumah sakit merupakan tempat yang menjadi harapan penyembuhan orang yang mengalami sakit, setiap yang datang berobat ke Rumah Sakit selalu berharap agar penyakitnya sembuh berkat bantuan pengobatan yang diberikan oleh dokter. Rumah sakit Islam di samping memberikan pengobatan secara medis juga memberikan layanan berupa bimbingan keagamaan yang diberikan oleh orang yang ahli yaitu konseris tujuannya agar pasien yang datang berobat mendapatkan layanan baik secara medis maupun mental. Untuk itu dibutuhkan peran konseris yang ada di Rumah Sakit Umum Aisyiyah Kota Padang untuk terus meningkatkan pelayanan bimbingan keagamaan sesuai dengan perkembangan kasus yang ada sehingga mampu memberikan ketenangan batin bagi orang sakit. Tujuan penelitian ini untuk mengetahui pelayanan bimbingan keagamaan yang diberikan di Rumah Sakit Umum Aisyiyah Kota Padang dari segi layanan dan bimbingan yang diberikan untuk pembinaan mental orang sakit. Target dan luaran yang akan dihasilkan berupa artikel ilmiah tentang peran konseris dalam pembinaan mental orang sakit melalui bimbingan keagamaan Islam.
\end{abstract}

Kata Kunci: Konselor Islam, Pembinaan Mental, Kerohanian Islam, Penyucian Jiwa 


\section{PENDAHULUAN}

Manusia dijadikan oleh Allah SWT sebagai khlifah dimuka bumi dengan segala kebihan dan potensi yang diberikan diharapkan mampu untuk hidup bahagia. Kehidupan yang bahagia tentu akan diperoleh dengan adanya kesehatan baik lahir maupun mental. Menurut Henderson bahwa aspek fisik dan spiritual tidak bisa dipisahkan satu dengan yang lainnya (Labola, 2018).

Hal ini sesuai dengan ilmu dan kiat keperawatan yang menyatakan bahwa pelayanan yang profesional adalah pelayanan yang memenuhi kebutuhan biopsiko-sosiospiritual yang komprehensif, yang ditujukan kepada individu, keluarga, dan masyarakat, baik sakit maupun sehat yang mencakup seluruh proses kehidupan manusia (Ake, 2002).

Pada dasarnya manusia menginginkan dirinya sehat, baik jasmani maupun rohani, Allah menurunkan al-Qur'an yang di dalamnya ada petunjuk dalam pengobatan terhadap penyakit yang menjangkit pada diri manusia baik fisik maupun psikis, sebagaimana dijelaskan dalam QS. Al-Isra: 82.

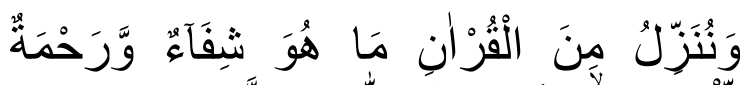

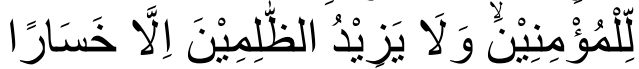
Artinya: Dan Kami turunkan dari al-Quran suatu yang menjadi penawar dan rahmat bagi orang-orang yang beriman dan al-Quran itu tidaklah menambah kepada orang-orang yang zalim selain kerugian.

Salah satu persoalan masyarakat terutama bagi mereka yang menderita penyakit kronis dan di rawat dirumah sakit adalah ketersediaan tenaga spiritual yang akan membimbing dan menguatkan psikis mereka (Nuraini, 2021). Minimnya tenaga konseris menyebabkan pelayanan spiritual pasien juga sangat terbatas (Arifin, 2012). Padahal pasien sangat memerlukan bantuan dalam rangka membangun keyakinan bahwa setiap penyakit ada obatnya. Di samping itu membangun rasa optimis dan bersabar dalam menghadapi cobaan dari Allah SWT.

Allah telah memerintahkan manusia untuk selalu sabar dalam menghadapi segala musibah yang dihadapinya, baik itu ujian, cobaan, ataupun peringatan dari Allah. Karena jika dia sabar, maka Allah akan menampakkan kebaikannya dengan tujuan agar selanjutnya manusia bisa memahami kemaslahatan yang tersembunyi dibalik itu (Al-Qarni, 2004).

Namun dalam kenyataannya sebagian besar orang yang menderita sakit di RSU Aisyiyah Kota Padang tidak bisa menerima keadaannya (Gamayanti, 2016). Dalam kondisi seperti ini mereka menghadapi dilema dan beban mental di luar kemampuannya. Seperti perasaan cemas, marah, tidak percaya diri dan mudah putus asa (Nida, 2014). 
Dengan kondisi semacam itu maka perlu adanya bimbingan keagamaan atau perawat rohani Islam bagi pasien rawat inap di RSU Aisyiyah Kota Padang melalui pembinaan Nafsul Mutma'innah, Tilawah, Tazkiyyah dan Ta'liman. Dengan demikian di harapkan agar pasien rawat inap mampu meningkatkan kualitas kesabaran dan kesadarannya dalam menghadapi musibah yang di alaminya. Sekaligus mampu meningkatkan motivasi untuk sembuh.

Oleh karena itu konseling Rohani Islam di RSU Aisyiyah Kota Padang dituntut untuk mengikuti perkembangan masyarakat yang semakin pesat sebagai akibat kemajuan iptek, khususnya teknologi komunikasi dan pengaruh global. Sehingga pembimbing rohani Islam harus mampu menyesuaikan dengan tuntutan zaman dan kebutuhan pasien (Khotimah, 2020a). Sehingga peran perawat rohani Islam bisa mewujudkan peran yang lebih baik dalam pembinaan psikis pasien di rumah sakit.

Untuk tuntutan itulah, pembimbing rohani Islam harus mampu mengemas dan menyajikan materi bimbingan rohani Islam, yang berhubungan dengan pembinaan Nafsul Mutma'innah, Tilawah, Tazkiyyah dan Ta'liman bagi pasien rawat inap di RSU Aisyiyah Kota Padang (Wardana, 2016).

Sehingga mampu memberikan pemahaman, motivasi, pengarahan, dan alternatif solusi dari sakit dan masalah yang dihadapi oleh pasien. Secara teoritis, manusia berunsurkan jasmaniah dan rohaniah (Myr dkk., t.t.). Sakit jasmaniah atau fisik biasanya ditangani oleh seorang ahli atau dokter sebagai orang yang dianggap paling tahu bagaimana cara penyembuhannya. Menyadari hal tersebut, maka menjadi penting pelayanan bimbingan rohani Islam secara profesional di RSU Aisyiyah Kota Padang (Wardana, 2016).

Untuk mencapai hal tersebut perlu dibangun adanya kesadaran dari beberapa kalangan yang bertanggung jawab terhadap kesehatan pasien rawat inap di RSU Aisyiyah Kota Padang baik dalam aspek jasmani maupun aspek rohani. Karena itu bimbingan rohani pasien di RSU Aisyiyah Kota Padang harus dikelola secara profesional dengan berbagai pelayanan (Wardana, 2016), yakni:

1. Bimbingan Nafsul Mutma'innah oleh konseris kepada orang sakit.

2. Bimbingan tilawah Al-Qur'an bagi orang sakit.

3. Bimbingan Tazkiah oleh konseris untuk orang sakit.

4. Bimbingan Ta'lim oleh konseris untuk orang sakit.

Metode yang digunakan juga harus komprehensif dengan metode lisan melalui ceramah individual dan kolektif serta metode tulisan melalui simbol agama, kaligrafi dan buku panduan agama (Riyadi, 
2012a). Kehadiran petugas rohani Islam di RSU Aisyiyah Kota Padang dengan berbagai pelayanan dan metodenya manjadi penting dalam rangka melengkapi aspek layanan yang seharusnya diterima setiap pasien rawat inap di RSU Aisyiyah Kota Padang, karena secara medis terapi yang berpengaruh kepada pasien tidak hanya psiko-farma, namun juga aspek lain seperti sosial dan religious (Wardana, 2016b)

Pelayanan kerohanian Islam tersebut tentunya tidak dapat dilakukan oleh sembarang orang, tetapi perlu dilakukan secara profesional oleh orang-orang yang memiliki kompetensi secara akademik dan skill (conceptual skill, human skill, dan technical skill) yang telah terlatih (Bukhori, 2005).

Hal ini menjadi sangat penting diperhatikan, karena pelayanan bimbingan kerohanian Islam di RSU Aisyiyah Kota Padang bukan hanya sebatas mendo'akan pasien sebagaimana yang diketahui kebanyakan orang. Namun lebih dari itu, bimbingan kerohanian Islam sangat dibutuhkan untuk membantu pasien memperoleh kesembuhan (Riyadi, 2012b).

Keberadaan layanan bimbingan kerohanian Islam di RSU Aisyiyah Kota Padang tentunya akan memberi dampak positif bagi kepuasan pasien sekaligus merupakan sebuah terobosan yang patut untuk dilakukan pihak rumah sakit sebagai bagian dari usaha meningkatkan mutu pelayanan dan mengembangkan citra positif di masyarakat.

Keberadaan bimbingan rohani Islam di RSU Aisyiyah Kota Padang juga bisa menjadi sebuah kekuatan baru dan gebrakan luar biasa apabila dikelola dan ditingkatkan kualitas pelayanannya untuk menghasilkan kepuasan pasien agar setia, dan konsisten untuk memanfaatkan Layanan Konseling Islam yang ada di RSU Aisyiyah Kota Padang. (Panjaitan, 2017)

Dengan demikian pelayanan bimbingan konseling kerohanian harus ditingkatkan kualitasnya dan dilakukan secara profesional demi mewujudkan visi dan misi rumah sakit. Meningkatkan mutu pelayanan yang memuaskan dan meningkatkan citra rumah sakit di mata masyarakat.

Dari uraian di atas, peneliti tertarik untuk mengadakan penelitian tentang pelaksanaan bimbingan rohani Islam bagi pasien rawat inap di RSU Aisyiyah Kota Padang (analisis bimbingan konseling Islam) dengan harapan dapat memberikan masukan dan kontribusi yang positif terhadap kualitas bimbingan kerohanian di RSU Aisyiyah Kota Padang dengan pendekatan konseling Islam, sehingga nantinya akan memberikan dorongan kepada pasien untuk menjalin ikatan yang kuat dengan petugas kerohanian khususnya di RSU Aisyiyah Kota Padang. Ikatan ini dalam jangka panjang akan 
memungkinkan petugas kerohanian memahami dengan seksama harapan dan kebutuhan mereka. Dengan demikian, petugas kerohanian dapat meningkatkan kapasitas diri menggunakan pengalaman dan mendorong serta memotivasi pasien untuk tegar menghadapi segala permasalahan hidup.

\section{METODE PENELITIAN}

Menurut (Suharsimi, 2006) metode penelitian adalah cara yang digunakan oleh peneliti dalam mengumpulkan data penelitiannya. Dalam penelitian ini metode yang digunakan adalah metode penelitian kualitatif. merupa-kan metode penelitian yang studi kasusnya mengarah pada pendeskripsian secara rinci dan mendalam mengenai potret kondisi tentang apa yang sebenarnya terjadi menurut apa adanya di lapangan studinya.

Jenis penelitian ini adalah penelitian lapangan field research yaitu penelitian yang objeknya mengenai gejala-gejala atau peristiwa-peristiwa yang terjadi pada kelompok masyarakat. Sehingga penelitian ini juga bisa disebut penelitian kasus atau study kasus (case study) dengan pendekatan deskriptif kualitatif (Arikunto, 2013).

Lokasi penelitian yang akan yang akan dilakukan ini di RSU Aisyiyah Kota Padang. Waktu yang dipergunakan untuk melaksanankan penelitian ini mulai dari bulan Juni sampai Desember 2020.
Penelitian

kualitatif

tidak dimaksudkan untuk membuat generalisasi dari hasil penelitiannya. Subjek penelitian yang telah tercermin dalam fokus penelitian tidak ditentukan secara sengaja. Subjek penelitian menjadi informan yang akan memberikan berbagai informasi yang diperlukan selama proses penelitian. Menurut (Rukajat, 2018) informan penelitian ini meliputi tiga macam yaitu:

1. Informan kunci (key informan), yaitu mereka yang mengetahui dan memiliki berbagai informasi pokok yang diperlukan dalam penelitian.

2. Informan utama, yaitu mereka yang terlibat secara langsung dalam interaksi sosial yang diteliti.

3. Informan tambahan, yaitu mereka yang dapat memberikan informasi walaupun tidak langsung terlibat dalam interaksi sosial yang diteliti.

Teknik pengumpulan data yang digunakan dalam penelitian ini adalah:

1. Observasi adalah dasar semua ilmu pengetahuan. Para ilmuwan hanya dapat bekerja berdasarkan data, yaitu fakta mengenai dunia kenyataan yang diperoleh melalui observasi (Semiawan, t.t.).

2. Wawancara adalah teknik pengumpulan data apabila peneliti akan melaksanakan studi pendahuluan untuk menemukan permasalahan yang harus diteliti, dan juga peneliti ingin mengetahui hal-hal 
lain dari responden yang lebih mendalam dan jumlah respondennya sedikit/kecil (Fadhallah, 2021). Wawancara yang digunakan dalam penelitian ini dengan mengajukan pertanyaan pertanyaan terstruktur karena peneliti menggunakan pedoman wawancara yang disusun secara sistematis dan lengkap untuk mengumpulkan data yang dicari

3. Dokumentasi. Metode dokumentasi adalah informasi yang berasal dari catatan penting baik dari lembaga atau organisasi maupun dari perorangan (Fatihudin dkk., 2020). Dokumentasi penelitian ini merupakan pengambilan gambar oleh peneliti untuk memperkuat hasil penelitian. Menurut (Sugiyono \& Kuantitatif, 2009), dokumentasi bisa berbentuk tulisan, gambar atau karyakarya monumental dari seseorang.

Teknik analisis data yang digunakan dalam penelitian ini menggunakan model Miles dan Hobermen.Analisi data dilakukan saat pengumpulan data berlangsung dan setelah selesai pengumpulan data dalam periode tertentu (Sugiyono, 2015). Proses analisis data ini dilakukandengan tahapan data reduction, data display dan conclusion/verification.

\section{HASIL DAN PEMBAHASAN}

\section{A. Hasil Penelitian}

Berikut ini akan dipaparkan hasil penelitian tentang peran konseris dalam pembinaan mental orang sakit di RSU Aisyiyah Kota Padang melalui kegiatan Nafsul Mutma'innah, Tilawah, Tazkiyyah dan Ta'liman.

\section{Peran Konseris Dalam Pembinaan Mental Orang Sakit Dalam Aspek Ketenangan Jiwa (Nafsul Mutma'innah) Di Rumah Sakit Umum Aisyiyah Kota Padang}

Kegiatan bimbingan konseling Islam di RSU Aisyiyah kota Padang sudah dilakukan sejak Tahun 2014. Sejak diadakannya kegiatan tersebut, diantara kegiatan layanan konseling yang dilakukan oleh konseris pada orang sakit yaitu, memberikan rasa senang saat tiba dan selama berada di rumah sakit adalah dengan memberikan pelayanan dengan pendekatan kekeluargaan dengan tidak membeda-bedakan latar belakang pasien. Disamping itu, konseris juga memberikan motivasi kepada pasien bahwa sakit itu adalah ujian dari Allah SWT (Winingsi, 2019).

Ujian ini diberikan kepada manusia semata-mata bukan karena Allah tidak sayang terhadap hambanya, namun dibalik sakit itu Allah SWT juga memberikan banyak hikmah (Fatmawati, 2013). Diantara hikmah yang Allah berikan adalah pengampunan terhadap dosa dan 
kesalahan yang pernah dilakukan dan doa orang yang sakit termasuk do'a yang makbul (NH, 2020).

Untuk memberikan ketenagan jiwa bagi pasien yang datang berobat ke RSU Aisyiyah Kota Padang, dengan senyum, menyapa, salam dan banyak menjalin komunikasi baik dengan pasien maupun dengan keluarga pasien. Memberikan semangat kepda pasien dan keluarga pasien agar yang sakit sabar dan keluarga juga sabar (Endah, 2014). Sabar dalam bentuk tindakan yang dapat diaplikasikan dengan cara berusaha untuk berobat sesuai anjuran dokter dan keluarga selalu sabar dalam bentuk selalu memotifasi orang yang sakit dengan menemaninya selama dirawat di rumah sakit. (FS, 2020)

Supaya pasien tidak gelisah dan merasa senang ketika datang kerumah sakit, diupayakan untuk menenangkannya karena banyak orang sakit banyak yang tidak menerima kondisinya (Agustini, 2016), disamping memberikan motivasi kepada pasien dan keluarga konseris juga menyarankan kepada pasien supaya banyak berzikir berdo'a dan bersabar karena sakit yang diberikan oleh Allah SWT merupakan bentuk kasih sayang-Nya juga kepad hamba-Nya (IQ, 2020). Juga menjelaskan banyak diantara pasien dari kalangan yang berbeda-beda dengan sikap yang berbeda pula dalam menghadapi sakit, konseris berusah untuk selalu memberikan pelayanan kelompok maupun individu, di samping itu proses pelayanan ini tetap diberikan kepada pasien sesuai kapasitasnya, karena ada juga pasien yang non muslim berobat disini, konseris tetap memberikan layanan untuk menenangkan jiwanya (Amal \& Khofsoh, 2018).

Dari apa yang penulis dapatkan di lapangan tentang peran konseris dalam memberikan ketenangan jiwa pada pasien di RSU Aisyiyah Kota Padang yang memberikan pelayanan atas asas kekeluargaan tergambar bahwa yang berobat ke RSU Aisyiyah Kota Padang di samping mayoritas muslim juga ada non muslim untuk itu kualitas konseris sangat dituntut keprofesinalannya dalam memberikan layanan dalam hal ini adalah layanan Nafsul Mutma'innah (Diniaty, 2013).

\section{Peran Konseris Dalam Pembinaan Mental Orang Sakit Melalui Membaca Al-Qur'an (Tilawah Al- Qur'an) Di RSU Aisyiyah Kota Padang}

Al-Qur'an merupakan kitab suci umat Islam dan membacanya merupakan ibadah yang besar (Atabik, 2014). Oleh sebab itu konseris tetap menganjurkan pasien untuk membaca lqur'an. Meskipun kegiatan ini baru bersifat memberikan anjuran, karena ketika konseris masuk ruangan banyak diantara pasien itu curhat tentang latar belakang kehidupan keluarganya tentu sebagai seorang konseris 
kita mendegar apa yang dikeluhkan pasien sebagai bentuk penghargaan padanya.

Kemudian sudah menjadi kebiasaan sebagian pasien sebelum sakit dia memang suka membaca Al-Qur'an dan ada juga yang tidak. Untuk pasien yang mungkin ketika sehat juga jarang membaca AlQur'an kita Cuma mengingatkan sebab kalau dibimbing tentu waktunya tidak maksimal. Karena konseris setiap hari itu harus masuk kesetiap ruangan pasien, di samping itu kenapa kita tidak sampai pada tahap membimbing baca Al-Qur'an karena keadaan pasien itu beragam ada yang cuman tiga hari sudah pulang. (NH, 2020b). Selanjutnya seperti disampaikan oleh, (IQ, 2020).

Program tilawah dalam pembinaan mental orang sakit sudah dilakukan diantaranya menyampaikan kepada pasien bahwa tilawah Al-Quran sangat baik diamalkan baik ketika sehat maupun sakit (Nurmiati, 2020). Diantara pasien ada yang mau dan ada juga yang tidak, bahkan ada pasien yang minta diajarkan karena ketika disuruh membaca Al-Qur'an mereka tidak bisa membaca, maka kita sebagai konseris dengan senang hati mengajarkannya walaupun belum bisa secara maksimal namun ini dilakukan dengan harapan agar pasien melanjutkannya setelah pulang.

Bagi pasien yang ingin membaca AlQur'an disetiap ruangan sudah disediakan mushaf Al-Qur'an terjemah sesuai dengan kebutuhan, artinya Al-Qur'an yang ada itu ukurannnya memang tidak besar, bagi yang membaca kalau kurang jelas bisa pakai kacamata, kalau ada isi kandungan Al-Quran yang kurang paham maknanya bisa diasampaikan nanti konseris akan membantu menjelaskan. Intinya untuk tiawah ini kita hannya bersifat anjuran belum sampai kepada keharusan mudahmudahan ini berlanjut. (FS, 2020)

Walaupun demikian dari hasil pengamatan penulis di lapangan, bahwa pembinaan tilawah atau membaca AlQur'an di RSU Aisyiyah masih sebatas anjuran atau imbauan terhadap pasiennya karena keterbatasan tenaga konseris.

\section{Peran Konseris Dalam Pembinaan Mental Orang Sakit Melalui Tazkiyyah (Pensucian Jiwa) Di RSU Aisyiyah Kota Padang}

Selama pasien dirawat terkadang prilaku pasien menggambarkan kebiasaan dia ketika sehat. Ada pasien bicara suka ngaur dan berkata tidak pada tempatnya, pasien yang baru datang terkadang dalam keadaan tidak sadar, lalu setelah sadar baru didekati dan ditanya bagaimana prilaku pasien dalam kesehariannya. Karena keadaan pasien yang datang itu bermacam pula bentuknya ada yang kukunya panjang-panjang ada juga yang penuh dengan tato. Oleh sebab itu seorang konseris tentu akan mendekatinya sesuai dengan pengalaman hidup pasien tersebut 
(Riyadi, 2012). Dilihat dari penampilan banyak sedikit pasien mengerti latar belakang kehidupan, setelah ditanya oleh konseris bagaimana ibadahnya dan prilakunya ketika sehat ternyata ada pasien itu yang pakai susuk dan tidak beribdah. Maka konseris mencoba memberikan motivasi supaya pasien meninggalkan segala perbuatan yang menyimpang itu dan menganjurkan pasien untuk taat beribadah (Andriyani, 2019). Dengan adanya bimbingan konseris ini diharapkan bisa menyadari akan arti kehidupannya di dunia ini, sehingga banyak juga pasien yang menangis setelah diberikan layanan bimbingan oleh konseris. ((NH, 2020b).

Berobat bagi orang sakit adalah kewajiban, makanya mengeluarkan harta untuk orang berobat juga merupak kewajiban yang akan diberikan balasan yang berlipat ganda oleh Allah SWT. Orang yang sakit juga akan digugurkan dosanya begitupan keluarga yang menemani dan memberikan semangat kepada saudaranya yang sakit juga merupakan obat asalkan dilandasi rasa keikhlasan dan sabar (Nawwir, 2021). Orang yang sabar dalam sakitnya adalah orang yang mau berobat dan mendengarkan apa kata dokter, demikian juga keluarga yang sabar akan selalu melakukan hal-hal yang membantu kesembuhan sisakit tidak putus asa.
Konseris juga memotivasi pasien bahwa saat sakit Allah SWT akan mengugurkan dosa-dosanya selanjutnya do'a-doa'nya juga diijabah Allah. Maka selama sakit jangan lupa doakan saudara yang menjaga, dokter yang merawat termasuk ustazd. Kemudian sakit juga memberikan waktu bagi kita untuk merenungkan tentang kelalaian kita mungkin ketika sehat kita sering lalai ibadah karena sibuk bekerja, kurang istirahat dan lalai menjaga pola makan (Romdiani, 2015). Kemudian selama sakit perbanyaklah untuk memberikan maaf kepada orang terhadap kesalahannya pada kita. Pada intinya tidak ada orang Islam ini yang ditimpa suatu musibah atau ujian kecuali Allah angkat derajatnya. (FS, 2020).

Memberikan pemahaman kepada manusia bahwa Allah memberikan nikmatNya kepada manusia tidak hannya berupa kesenangan namun, juga dalam bentuk sakit karena dengan sakit itu terkadang Allah SWT mengingatkan tentang kelalaian kita dan juga menyelamatkan kita dari dosa yang pernah kita lakukan. (IQ, 2020)

Oleh karena itu, salah satu bentuk kegiatan yang dilakukan di RSU Aisyiyah dalam rangka Tazkiyyah adalah dengan memberi ceramah singkat kepada pasien tentang hikmah sakit dan pentingnya sabar dalam menghadapi sakit. Sakit akan 
mengingatkan seseorang terhadap pentingnya mensyukuri kesehatan, sehinnga timbul motivasi pasien untuk sembuh.

\section{Peran Konseris Dalam Pembinaan Mental Orang Sakit Melalui Ta'lim (Ceramah Singkat) Di RSU Aisyiyah Kota Padang}

Ta'liman adalah proses mentransfer pengetahuan dan memberi Pendidikan ruhiyah terhadap pasien agar lebih kuat dalam menghadapi ujian yang diterimanya (Mustakim, 2012). Untuk Ta'liman kepada pasien Rumah Sakit sudah punya panduan dari pimpinan pusat. Buku tentang panduan orang sakit tentang do'a apa saja yang mesti diamalkan oleh orang yang sakit. Ada berupa buku panduan do'a yang bisa dibaca oleh pasien misalnya ketika mau melahirkan apa do'a yang mesti dibaca dan itu dulu diberikan kepasien, namun sekarang karena pasien kita banyak BPJS sehingga untuk mencetak buku tersebut kita terkendala biaya, namun kita sebagai konseris selalu berusaha untuk mekanjutkan itu walaupun hasilnya belum maksimal namun akan terus berusaha supaya pelayanan ini akan terus diupayakan sehingga jadi maksimal. (NH, 2020a)

Menurut IQ (2020) mengatakan diasamping ada buku panduan bagi orang sakit, konseris lebih menekankan kepada pasien bagaimana memanfaatkan waktu ketika sakit, berpikiran positif terhadap sakit yang diberikan oleh Allah SWT, kemudian orang sakit bisa lebih displin baik dalam hal kebuthan fisiknya maupun ibadahnya. Orang yang sakit bisa lebih banyak baca Al-Qur'an lebih disiplin dalam melaksanakan shalat.

Ta'liman yang diberikan memang diutamakan masalah ibadah yang utama yaitu shalat, jangan sampai tinggal shalat pada saat sakit karena sakit itu banyak kemudahanya. Kalau tidak bisa berwudhu' bisa bertayamum tidak harus dengan debu yang menempel di dinding dibantal, bahkan dia bisa tahajut setiap malam karena dia sudah terbaring juga. Lalu disampaikan juga orang sakit bisa lebih tepat waktu dalam beribadah bahkan bisa shalat tahajut tiap malam karena, orang sehat saja belum tentu shalat tepat waktu karena sibuk bekerja. Orang yang sakit juga diberikan waktu untuk betanya kalau ada yang mesti diperjelas di samping itu pasien juga dianjurkan untuk rajin bertanya juga kepada dokter.

Dengan adanya musibah sakit rasa kekluargaan semakin terasa erat, karena dengan adanya sakit seorang bisa sekamar dengan orang tua, kakak, adik saudara sampai satu atau dua hari yang pada hari lain belum tentu bisa, dari apa yang disampaikan konseris mendapat berbagai tanggapan umumnya merasa senang dengan pelayanan yang diberikan, bahkan ada saudagar kaya cina mengatakan bahwa pelayanan disini no wahid saya sangat 
senang. Memang kita katakan kepada perawat saat mengantarkan makanan supaya menyapa pasien dengan memotivasinya unutuk makan. Umumnya setiap materi yang disampaikan diterima baik oleh pasien (FS, 2020).

Dari paparan yang disampaikan penulis dapat menyimpulkan bahwa materi yang diberikan oleh konseris lebih mengacu pada ibadah shalat, memotivasi pasien untuk tetap tertip ibadah walaupun dalam keadaan sakit (Ni'mah, 2015). selanjutnya penulis berpendapat untuk lebih menyentuh pada persoalan yang dihadapi pasien disamping ibadah permasalahan yang berkaitan dengan psikologinya juga harus dikejar sebab orang yang sakit disamping rohani (jiwa) juga lebih penting menggali akar persoalan yang juga mungkin tersimpan oleh pasien sehingga, pasien yang sakit merasa benar-benar terbantu baik dari segi mental maupun psikisnya (Khotimah, 2020).

\section{KESIMPULAN}

Dari data yang penulis dapatkan di lapangan kegiatan bimbingan dilakukan oleh konseris sudah dimulai semenjak 2014, namun belum berjalan dengan maksimal. Untuk proses bimbingan sudah ada buku panduannya dari pusat konseris tinggal melaksanakan sesuai dengan yang ada di buku panduan. Pasien yang berobat ke RSU Aisyiyah Kota Padang biasanya diberikan buku panduan tentang keistimewaan orang sakit namun karena sekarang pasien yang berobat sudah menggunankan BPJS konseris tidak lagi memiliki dana untuk mengkopi buku tersebut.

Pelayanan yang diberikan berdasarkan data yang penulis dapatkan untuk menenangkan jiwa pasien konseris dan karyawan di RSU Aisyiyah Kota Padang menerapkan senyum salam sapa dan jalin komunikasi, karena pasien yang datang berasal dari berbagai kalangan dan daerah yang berbeda maka pelayanan yang diberikan mesti disesuaikan dengan keadaan pasien. Untuk program tilawah bagi pasien baru sebatas bersifat anjuran, disebabkan pasien hannya ada dua atau seminggu mereka sudah pulang disamping itu ada juga yang minta diajarkan. Pelayanan tazkiyyah dikhususkan pada pembinaan ibadah supaya pasien tidak tinggal ibadahnya walaupun dalam keadaan sakit. Program layann ta'liman diberikan kepada pasie disaat dokter selesai memantau pasien dan juga dilaksanakan di Mushalla. Dari materi yang diberikan juga mendapat tanggapan yang positif dari pasien.

Penelitian ini diharapkan dapat memberikan sumbangan pemikiran untuk kemajuan bimbingan pelayanan konseris di RSU Aisyiyah Kota. Selanjutnya bagi penelitia selanjutnya dapat digunakan ntuk menambah wawasan dan memperkaya 
keilmuan penulis dalam bidang penelitian dan bidang bimbingan rohani Islam.

\section{REFERENSI}

Agustini, M. (2016). Self-efficacy dan makna hidup pada penderita penyakit jantung koroner. Psikoborneo: Jurnal Ilmiah Psikologi, 4(1).

Ake, J. (2002). Malpraktik dalam Keperawatan. Buku Kedokteran EGC.

Al-Qarni, A. (2004). La Tahzan. Terjamah. Qisti Press.

Amal, A. I., \& Khofsoh, E. (2018). Potret Kebutuhan Spiritual Pasien HIV/AIDS. Unissula Nursing Conference Call for Paper \& National Conference, 1(1), 70-74.

Andriyani, A. (2019). Peran Bimbingan Rohani Islam Dalam Membangun Motivasi Pasien Korban Kecelakaan Di Rs. Bunda Way Kanan [PhD Thesis]. UIN Raden Intan Lampung.

Arifin, I. Z. (2012). Bimbingan dan Konseling Islam untuk Pasien Rawat Inap di Rumah Sakit. Ilmu Dakwah: Academic Journal for Homiletic Studies, 6(1), 170-194.

Arikunto, S. (2013). Dasar-dasar Evaluasi Pembelajaran Kooperatif. Bumi Aksara.

Atabik, A. (2014). The Living Qur'an: Potret Budaya Tahfiz al-Qur'an di Nusantara. Jurnal penelitian, 8(1), 161-178.

Bukhori, B. (2005). Upaya Optimalisasi Sistem Pelayanan Kerohanian bagi Pasien RawatInap. Semarang: Walisongo.

Diniaty, A. (2013). Urgensi Teori Konseling dan Perspektifnya dalam Islam Menjawab Tuntutan Konseling Religius di Masa Depan. Al-Ta lim Journal, 20(1), 312-232.

Endah, R. N. (2014). Peran Perawat Rohani Islam dalam Membimbing Kesabaran Pasien (Studi Deskriptif Bimbingan Rohani Islam Ruang
Rawat Inap Rumah Sakit Umum Daerah Kota Bandung) [PhD Thesis]. UIN Sunan Gunung Djati Bandung.

Fadhallah, F. (2021). Wawancara. UNJ PRESS.

Fatihudin, D. F., Holisin, I. H., Soebardhy, S., Samani, M. S., Ibrahim, M. I., MA, D. I., PH, D. H. W., \& M.Pd, D. A. A. (2020). KAPITA SELEKTA METODOLOGI PENELITIAN. Penerbit Qiara Media.

Fatmawati, L. (2013). Optimalisasi Layanan Bimbingan Rohani Islam bagi Pasien Rawat Inap di Rumah Sakit Roemani Muhammadiyah Semarang [PhD Thesis]. IAIN Walisongo.

FS, F. (2020). Wawancara.

Gamayanti, W. (2016). Gambaran penerimaan diri (self-acceptance) pada orang yang mengalami skizofrenia. Psympathic: Jurnal Ilmiah Psikologi, 3(1), 139-152.

IQ. (2020). Wawancara.

Khotimah, S. (2020a). Peran Pembimbing Rohani Islam dalam Menurunkan Stress pada Pasien Gagal Ginjal Kronik di RSI Arafah Rembang [PhD Thesis]. IAIN KUDUS.

Khotimah, S. (2020b). Peran Pembimbing Rohani Islam dalam Menurunkan Stress pada Pasien Gagal Ginjal Kronik di RSI Arafah Rembang [PhD Thesis]. IAIN KUDUS.

Labola, Y. A. (2018). Perpaduan Kecerdasan Intelektual (IQ), Emosional (EQ) dan Spiritual (SQ) Kunci Sukses bagi Remaja. Share: Social Work Journal, 8(1), 39-45.

Mustakim, M. (2012). Ontologi Pendidikan Islam. Jurnal Ilmu Tarbiyah" At-Tajdid, 1(2), 164.

MYR, B. M., IDR, B. I., Wanita, B., Muslim, B., Branded, B., Diskon, B., Batik, B., Lucu, K., Dalam, P., \& Pria, B. (t.t.). Tampilkan Ukuran. 
Nawwir, Y. (2021). Penyakit dalam Perspektif Ihsan. Jurnal Ilmiah Islamic Resources, 17(2), 56-62.

NH. (2020a). Wawancara.

NH, N. (2020b). Wawancara.

Nida, F. L. K. (2014). Zikir sebagai PsikoteraPi dalam gangguan kecemasan bagi lansia. Konseling Religi, 5(1).

Ni'mah, R. F. (2015). Pelaksanaan bimbingan agama Islam tentang kedisiplinan shalat lima waktu di panti wredha Harapan Ibu Ngaliyan Semarang [PhD Thesis]. UIN Walisongo.

Nuraini, T. S. (2021). Peran Pekerja Sosial Rohani Bagi Kesejahteraan Pasien Rawat Inap Di Rumah Sakit Pku Aisyiyah BoyolalI.

Nurmiati, U. (2020). Terapi Sufistik dalam mengobati penyakit hati: Studi deskriftif Tarekat Idrisiyyah Jl Raya Ciawi KM 8 No. 79 Pagendingan, Desa Jatihurip Kec. Cisayong Kab. Tasikmalaya [PhD Thesis]. UIN Sunan Gunung Djati Bandung.

Panjaitan, N. S. (2017). Bentuk bimbingan rohani dalam mengatasi stres pada pasien rumah sakit umum Muhammadiyah Sumatera Utara $[\mathrm{PhD}$ Thesis]. Universitas Islam Negeri Sumatera Utara.

Riyadi, A. (2012a). Dakwah terhadap Pasien (Telaah terhadap Model Dakwah melalui Sistem Layanan Bimbingan Rohani Islam di Rumah Sakit). Dalam Konseling Religi: Jurnal Bimbingan Konseling Islam, $3(2)$.

Riyadi, A. (2012b). Dakwah terhadap Pasien (Telaah terhadap Model Dakwah melalui Sistem Layanan Bimbingan Rohani Islam di Rumah Sakit). Dalam Konseling Religi: Jurnal Bimbingan Konseling Islam, $3(2)$.

Romdiani, E. (2015). Pengaruh Bimbingan Agama Islam Melalui Pendekatan Do'a Terhadap Motivasi Kesembuhan Pasien Rawat Inap di
Rumah Sakit Umum Daerah (RSUD) Kota Bandung [PhD Thesis]. UIN Sunan Gunung Djati Bandung.

Rukajat, A. (2018). Pendekatan Penelitian Kualitatif (Qualitative Research Approach). Deepublish.

Semiawan, P. D. C. R. (t.t.). Metode Penelitian Kualitatif. Grasindo.

Sugiyono, M. P. P., \& Kuantitatif, P. (2009). Kualitatif, dan R\&D, Bandung: Alfabeta. Cet. VII.

Suharsimi, A. (2006). Metodelogi Penelitian. Yogyakarta: Bina Aksara.

Wardana, A. K. (2016a). Pelaksanaan bimbingan rohani Islam bagi pasien rawat inap di rumah sakit Islam Sultan Agung Semarang (analisis bimbingan konseling Islam) [PhD Thesis]. UIN Walisongo.

Wardana, A. K. (2016b). Pelaksanaan bimbingan rohani Islam bagi pasien rawat inap di rumah sakit Islam Sultan Agung Semarang (analisis bimbingan konseling Islam) [PhD Thesis]. UIN Walisongo.

Winingsi, Y. (2019). Aktivitas Konseris dalam Membantu Pasien Rawat Inap Bangsal Bedah di RSUD $\mathrm{M}$. Zein Painan. Jurnal Al-Irsyad: Jurnal Bimbingan Konseling Islam, 1(2), 187-200. 